\title{
Food addiction: Prevalence, psychopathological correlates and associations with quality of life in a large sample
}

\author{
Paulo R. Nunes-Neto ${ }^{\text {a }}$, Cristiano A. Köhler ${ }^{\mathrm{a}}$, Felipe B. Schuch ${ }^{\mathrm{b}, \mathrm{c}}$, Marco Solmi ${ }^{\mathrm{d}, \mathrm{e}}$, \\ João Quevedo ${ }^{\mathrm{f}, \mathrm{g}, \mathrm{h}, \mathrm{i}}$, Michael Maes ${ }^{\mathrm{j}, \mathrm{k}}$, Andrea Murrul, Eduard Vieta ${ }^{1}$, Roger S. McIntyre ${ }^{\mathrm{m}, \mathrm{n}, \mathrm{o}}$, \\ Susan L. McElroy ${ }^{\mathrm{p}, \mathrm{q}}$, Ashley N. Gearhardt ${ }^{\mathrm{r}}$, Brendon Stubbs ${ }^{\mathrm{e}, \mathrm{s}, \mathrm{t}, \mathrm{u}}$, André F. Carvalho ${ }^{\mathrm{a}, \mathrm{e}, *}$ \\ a Translational Psychiatry Research Group and Department of Clinical Medicine, Faculty of Medicine, Federal University of Ceará, Fortaleza, CE, Brazil \\ b Mestrado em Saúde e Desenvolvimento Humano, Universidade La Salle, Canoas, RS, Brazil \\ ${ }^{\mathrm{c}}$ Hospital de Clínicas de Porto Alegre, Porto Alegre, RS, Brazil \\ d Neuroscience Department, University of Padua, Padova, Italy \\ e Institute for Clinical Research and Education in Medicine (IREM), Padua, Italy \\ ${ }^{\mathrm{f}}$ Translational Psychiatry Program, Department of Psychiatry and Behavioral Sciences, McGovern Medical School, The University of Texas Health Science Center at \\ Houston (UTHealth), Houston, TX, USA \\ ${ }^{\mathrm{g}}$ Laboratory of Neurosciences, Graduate Program in Health Sciences, Health Sciences Unit, University of Southern Santa Catarina (UNESC), Criciúma, SC, Brazil \\ ${ }^{\text {h }}$ Center of Excellence on Mood Disorders, Department of Psychiatry and Behavioral Sciences, McGovern Medical School, The University of Texas Health Science Center at \\ Houston (UTHealth), Houston, TX, USA \\ ${ }^{\mathrm{i}}$ Neuroscience Graduate Program, The University of Texas MD Anderson Cancer Center UTHealth Graduate School of Biomedical Sciences, Houston, TX, USA \\ ${ }^{j}$ Department of Psychiatry, Faculty of Medicine, Chulalongkorn University, Bangkok, Thailand \\ k IMPACT Research Center, Deakin University, Geelong, Australia \\ ${ }^{1}$ Bipolar Disorders Unit, Institute of Neuroscience, Hospital Clínic, University of Barcelona, IDIBAPS, CIBERSAM, Barcelona, Catalonia, Spain \\ $\mathrm{m}$ Department of Psychiatry, University of Toronto, Ontario, Canada \\ ${ }^{n}$ Mood Disorders Psychopharmacology Unit, University Health Network, Toronto, Ontario, Canada \\ o Department of Pharmacology, University of Toronto, Ontario, Canada \\ p Lindner Center of HOPE, Mason, OH, USA \\ ${ }^{\mathrm{q}}$ University of Cincinnati College of Medicine Department of Psychiatry and Behavioral Neuroscience, Cincinnati, OH, USA \\ ${ }^{\mathrm{r}}$ Department of Psychology, University of Michigan, Ann Arbor, MI, USA \\ s South London and Maudsley NHS Foundation Trust, Denmark Hill, London, SE5 8AZ, United Kingdom; \\ ${ }^{\mathrm{t}}$ Institute of Psychiatry, Psychology and Neuroscience (IoPPN), King's College London, De Crespigny Park, London, SE5 8 AF, United Kingdom \\ ${ }^{\mathbf{u}}$ Faculty of Health, Social Care and Education, Anglia Ruskin University, Chelmsford, CM1 1SQ, United Kingdom
}

\section{A R T I C L E I N F O}

\section{Keywords:}

Food addiction

Psychiatry

Epidemiology

Mood disorders

Behavioural addictions

Psychopathology

\begin{abstract}
A B S T R A C T
Objective: To determine the prevalence of food addiction in a large Brazilian non-clinical sample. Sociodemographic and psychopathological correlates of food addiction as well as associations with quality (QoL) domains were also investigated.

Methods: This cross-sectional study obtained data from a Brazilian anonymous web-based research platform ( $\mathrm{N}=7639 ; 71.3 \%$ females). Participants provided sociodemographic data and completed the modified Yale Food Addiction Scale 2.0, PHQ-9, hypomania checklist (HCL-32), Fagerström Test for Nicotine Dependence, AUDIT, modified Skin picking-Stanford questionnaire, Minnesota impulsive disorders interview, Symptom Checklist-90-Revised inventory (SCL-90R), early trauma inventory self report-short form, and the WHO Quality of Life instrument-Abbreviated version (WHOQOL-Bref). Associations were adjusted to potential confounders through multivariable models.

Results: The prevalence of food addiction was 4.32\% (95\%CI: 3.89-4.80\%), and was more common among females. Food addiction was associated with a positive screen for a major depressive episode $(\mathrm{OR}=4.41$; 95\%CI: 3.46-5.62), bipolar spectrum disorder (OR $=1.98$; 95\%CI: 1.43-2.75), and skin picking disorder $(\mathrm{OR}=2.02$; 95\%CI: 1.31-3.09). Food addiction was also independently associated with exposure to early life psychological and sexual abuse $(P=0.008)$ as well as with reduced physical, psychological, social, and environment QoL (all $\mathrm{P}<0.001$ ).

Conclusions: Food addiction may be common in low and middle-income countries, though possibly less prevalent than in the US. Food addiction was associated with co-occurring mood disorders and skin picking disorder as
\end{abstract}

\footnotetext{
* Corresponding author. Department of Clinical Medicine, Faculty of Medicine, Federal University of Ceará, Rua Prof. Costa Mendes $1608,4^{\circ}$ andar, $60430-160$, Fortaleza, CE, Brazil.

E-mail address: andrefc7@hotmail.com (A.F. Carvalho).
} 
well as with early life psychological and sexual abuse. Finally, food addiction was independently associated with broad reductions in QoL. Public health efforts towards the early recognition and management of food addiction are warranted.

\section{Introduction}

Evidence indicates that the consumption of highly processed, energy-dense food may be accompanied by functional alterations in brain reward system networks and neurotransmitter pathways (for example, dopaminergic and opioidergic systems) that also subserve putative neurobiological responses to drugs of abuse (Volkow et al., 2013a, 2016). Furthermore, it has been increasingly recognized that a subset of individuals may develop food addiction, a construct that encompasses behavioural features of eating that are also evident in people with substance use disorders (SUDs), including impulsivity, impaired control, functional impairment, and tolerance and withdrawal (Schulte et al., 2016). A self-report instrument referred to as the Yale Food Addiction Scale (YFAS) was developed based on DSM-IV-TR criteria for substance dependence (Gearhardt et al., 2009b). The YFAS has been validated across several languages and cultures, and evidence to date supports its robust psychometric properties, which are indicated by an adequate internal consistency reliability, a single-factor structure, and adequate convergent and discriminant validities compared to related constructs (e.g. weight cycling and binge eating) (Gearhardt et al., 2009a, b; Meule and Gearhardt, 2014). More recently, up-dated versions of the YFAS (i.e., the YFAS 2.0 and the briefer mYFAS 2.0) were developed to reflect DSM-5 criteria for SUDs (Gearhardt et al., 2016; Schulte and Gearhardt, 2017). Both the YFAS 2.0 and the mYFAS 2.0 instruments display consistent and adequate psychometric properties (Gearhardt et al., 2016; Schulte and Gearhardt, 2017).

A recent meta-analysis found a weighted prevalence of food addiction as assessed with different versions of the YFAS of 19.9\%, with most included studies conducted in the US (Pursey et al., 2014). However, heterogeneity across studies was high (prevalence range: $5.4 \%-56.8 \%$ ), with higher prevalence rates observed in studies that included clinical samples seeking treatment for overweight/obesity, as well as in studies with a higher prevalence of females in the sample (Pursey et al., 2014). Importantly, none of the component studies of this meta-analysis were conducted in low and middle-income countries (LMICs) (Pursey et al., 2014). Furthermore, relatively few studies have investigated the prevalence of co-occurring mental disorders and psychopathological correlates among individuals with food addiction. Available evidence suggests that food addiction is associated with a higher prevalence of depressive and anxiety symptoms (Chao et al., 2017b; Gearhardt et al., 2009b; Meule et al., 2014). The association of food addiction and alcohol and nicotine use disorders remain unclear. One study found that current smokers may have higher craving scores for highly palatable foods, whilst another study found that food addiction was not associated with tobacco use (Berenson et al., 2015; Chao et al., 2017b). In addition, food addiction and binge eating frequently co-occur (Gearhardt et al., 2014, 2013, 2012), and food addiction may predict binge-eating frequency more accurately than other factors related to binge-eating, such as negative affect eating disorder psychopathology (Gearhardt et al., 2012). Thus, these findings suggest that food addiction and disorders with binge-eating are overlapping, yet distinct constructs (Schulte et al., 2016). In addition, exposure to severe physical and sexual abuse during childhood was associated with a higher risk to develop food addiction among women (Mason et al., 2013). Moreover, the independent associations of food addiction and different quality of life (QoL) domains in non-clinical samples remain unclear.

Although skin picking disorder (SPD) and trichotillomania (TTM) are currently classified in the DSM-5 as obsessive-compulsive and related disorders (Stein et al., 2016), a growing body of evidence indicates that these disorders share epidemiological, phenomenological, and neurobiological characteristics with SUDs and gambling disorder (Chamberlain et al., 2016; Figee et al., 2016). Therefore, some experts have proposed that skin picking disorder and trichotillomania could also be conceptualized as 'behavioural addictions' taking into account trans-diagnostic frameworks, such as the NIMH Research Domain Criteria (Chamberlain et al., 2016; Cuthbert and Insel, 2013). In addition, a recent study suggests that higher food addiction scores may be associated with detrimental psychopathological correlates in a treatment-seeking sample with gambling disorder (Jimenez-Murcia et al., 2017). However, no study has investigated associations of food addiction with skin picking disorder and trichotillomania.

Given the aforementioned gaps in the literature, the current study had three aims: (1) to estimate the prevalence and sociodemographic correlates of food addiction in a large web-based Brazilian sample; (2) to assess psychopathological correlates of food addiction including a positive screen for nicotine dependence, alcohol use disorder, major depressive episode, bipolar spectrum disorder, SPD, trichotillomania, and early life trauma with validated self-report measures; and (3) to determine the independent association of food addiction and QoL domains. We hypothesized that food addiction could be prevalent in our sample (which is derived from a LMIC i.e. Brazil), and that significant associations between food addiction and a positive screen for affective disorders, alcohol use disorder, nicotine dependence, SPD, and TTM. Finally, we hypothesized that the participants with food addiction could have a more impaired QoL compared to those without food addiction after multivariable adjustment to sociodemographic and psychopathological confounding variables.

\section{Methods}

\subsection{Sample selection}

Consecutive participants $(\mathrm{N}=9603)$ were recruited through a large web-based Brazilian study (Portal Temperamento e Saúde Mental, www.temperamentoesaudemental.org) (Lima et al., 2017). This website provides an encrypted and confidential platform for data collection. The research ethics committee of the Hospital Universitário Walter Cantídio (HUWC) approved the procedures for online data collection under the protocol number 1.058.252. To access the surveys, participants were required to be at least 18 years old and to sign a digital informed consent form. Validation and attention questions throughout the protocol were employed to assess data quality. Examples of questions included for example "How old are you?" and "How much attention are you paying while answering to this survey?". Consistency of responses were verified (i.e., participants had previously provided their dates of birth), and also participants who indicated that they were not paying adequate attention to the questionnaires were excluded. Therefore, this study included participants who had provided valid responses to these questions. From the initial sample, 9585 participants answered the complete survey, and after quality checking 7639 subjects remained eligible and were included in the analyses (response rate: 79.7\%). There were no statistically significant differences between participants who were not included in the final sample compared to those that did not pass our quality check in sociodemographic variables (data available upon request to the authors).

This online survey collected sociodemographic data (age, sex, educational level, ethnicity, marital status, religious affiliation, occupation, and gross monthly income). In addition, this web-based platform included several validated psychological and psychiatric measures, which 
are described below.

\subsection{Measures}

\subsubsection{Modified Yale Food Addiction Scale 2.0 (mYFAS 2.0)}

The presence of addiction was assessed with the validated Brazilian version of the mYFAS 2.0 (Paulo Nunes-Neto MD, submitted), a selfreport instrument composed of 13 Likert-type items. Eleven items are based on DSM- 5 criteria for SUDs, while the remaining 2 items refer to the clinical significance of the symptoms. In addition to screening for the presence of food addiction, which requires the presence of at least two symptoms plus impairment or distress, the mYFAS 2.0 also rates the severity of food addiction as mild (2-3 symptoms plus impairment or distress), moderate (4-5 symptoms plus impairment or distress), or severe (more than six symptoms plus impairment or distress). The Cronbach's alpha coefficient of the mYFAS 2.0 in the current sample was 0.89 (95\% CI: 0.89-0.90).

\subsubsection{Patient Health Questionnaire-9 (PHQ-9)}

Depressive symptoms were assessed with the validated Brazilian Portuguese version of the PHQ-9 (Santos et al., 2013). The PHQ-9 questionnaire is a self-report instrument that employs the nine DSM-IV symptom-based criteria for screening of major depressive episodes (Kroenke et al., 2001). A positive screening for a major depressive episode was established based on an algorithm in accordance with the validation study of the Brazilian Portuguese version of the PHQ-9, which was performed in the general population (Santos et al., 2013). Question 9 of the PHQ-9 (i.e. "Having thoughts that you would be better off dead, or of hurting yourself on at least 2 days over the past 2 weeks") was used to screen for the presence of suicidal ideation (Choi and Lee, 2017).

\subsubsection{Hypomania checklist (HCL-32)}

The HCL-32 investigates the presence of a wide range of (hypo) manic symptoms with 32 yes/no questions (Angst et al., 2005). Participants were asked to focus on the 'high' periods and to indicate whether hypomanic manifestations were present during this state. In addition, the HCL-32 includes eight severity and functional impact items related to the duration of episodes and to positive and negative consequences over different areas of functioning. We used the validated Brazilian Portuguese version of the HCL-32 with the recommended cutoff of 19 for non-clinical samples (Soares et al., 2010). In addition, for a positive screening for a bipolar spectrum disorder, participants had to endorse an impairment in at least one area of functioning due to the presence of hypomanic symptoms. A previous meta-analysis supports the accuracy of the HCL-32 for the screening of bipolar spectrum disorders (Carvalho et al., 2015).

\subsubsection{Fagerström Test for Nicotine Dependence (FTND)}

We used the validated Portuguese version of the FTND to screen for the presence of DSM-IV nicotine dependence(de Meneses-Gaya et al., 2009). The FTND is a six-item self-report questionnaire with scores ranging from 0 to 10 (Heatherton et al., 1991). A cutoff score of 4 on the FTND was considered as indicative of nicotine dependence in the current study (de Meneses-Gaya et al., 2009).

\subsubsection{Alcohol Use Disorders Identification Test (AUDIT)}

We used the validated Brazilian Portuguese version of the AUDIT to screen for the presence of alcohol use disorders (Lima et al., 2005). The AUDIT is a 10-item self-report questionnaire developed by the World Health Organization (WHO) to screen for the presence of alcoholism (formerly referred to as hazardous or harmful alcohol consumption) (Saunders et al., 1993). In this study, a score $\geq 8$ was considered indicative of the presence of an alcohol use disorder (Saunders et al., 1993).

\subsubsection{Skin picking stanford questionnaire (SPSQ)}

The SPSQ is self-report measure consisting of 13 questions that address the phenomenology of SPD using a yes/no/don't know format (Keuthen et al., 2010; Monzani et al., 2012). We decided a priori to eliminate from the original version of the questionnaire the question "Could you write the name of that medical condition?", which refers to a possible underlying medical condition that could explain the skin picking behavior. This question is not essential to the case definition of SPD based on DSM-5 criteria (American Psychiatric Association, 2013). However, we maintained the question, "Do you pick your skin because it is inflamed or itchy due to a medical condition?" consistent with the DSM-5 exclusion criterion. This modified version of the SPSQ has been validated for use in Brazilian samples (Myrela O. Machado MD, submitted).

\subsubsection{Minnesota impulse disorders interview (MIDI)}

The used the TTM module of the MIDI as self-report screening instrument (Christenson et al., 1994; Odlaug and Grant, 2010a). For the purposes of the present study, we used the validated Brazilian TTM module of the MIDI (Myrela O. Machado MD, in preparation) to screen for the presence of lifetime TTM.

\subsubsection{Symptom Checklist-90-revised inventory (SCL-90R)}

We used the Brazilian Portuguese version of the Symptom Checklist90-Revised inventory (SCL-90R) to assess psychopathological dimensions (Carissimi, 2011; Derogatis and Melisaratos, 1983). Briefly, the SCL-90R is a 90-item 5-point Likert-type inventory, which assesses several psychopathological dimensions namely somatization, obsessivecompulsive, interpersonal sensitivity, depression, anxiety, hostility, phobic anxiety, paranoid ideation, and psychoticism.

\subsubsection{Early trauma inventory self report -short form (ETISR-SF)}

We used the validated Brazilian Portuguese version of the ETISR-SF to assess exposure to early trauma (Osorio et al., 2013). This is a selfreport instrument consisting of 27 items grouped into four dimensions (general trauma, physical abuse, emotional abuse, and sexual abuse) (Bremner et al., 2007).

\subsubsection{World Health Organization quality of life instrument-abbreviated version (WHOQOL-Bref)}

We used the validated Brazilian Portuguese version of the WHOQOL-Bref to assess QoL in the current study (Fleck et al., 2000). This instrument consists of 26 items assessing QoL in four dimensions, namely physical, psychological, social, and environment QoL (WHOQOL-Group, 1998). Each item is rated on a 5-point Likert-type scale, and scores are transformed on a scale from 0 to 100 , with higher scores indicating higher QoL.

\subsection{Statistical analysis}

All statistical analyses were carried out in SPSS (IBM, US) version 22.0 for Windows. Continuous variables are presented as means \pm standard deviations (SD). The Kolmogorov-Smirnov test was used to assess whether variables displayed a normal distribution. Sociodemographic and psychopathological variables were compared between participants with versus those without food addiction. Normally distributed continuous variables were compared using independent samples Student's-t-test. Categorical variables were compared using Pearson's chi-square $\left(\chi^{2}\right)$ or Fisher's Exact Test as appropriate.

The associations of food addiction (dependent variable) and a positive screen for a major depressive episode, bipolar spectrum disorder, alcohol or tobacco use disorder, suicidal ideation, SPD, trichotillomania, early life trauma, and SCL-90R psychopathological domains were assessed using separate multivariable logistic regression models. For the association of food addiction and psychopathological 
Table 1

Sociodemographic and psychopathological characteristics of study participants.

\begin{tabular}{|c|c|c|c|c|}
\hline Variable & $\begin{array}{l}\text { Total } \\
(\mathrm{N}=7639)\end{array}$ & $\begin{array}{l}\text { FA } \\
(\mathrm{N}=330)\end{array}$ & $\begin{array}{l}\text { No FA } \\
(\mathrm{N}=7309)\end{array}$ & $P$-value \\
\hline Age, years (mean \pm SD) & $27.2 \pm 7.9$ & $27.1 \pm 7.4$ & $27.2 \pm 7.9$ & $0.905^{\mathrm{c}}$ \\
\hline \multicolumn{5}{|l|}{ Age range } \\
\hline 18-21 years & $1817(23.8)$ & $82(24.8)$ & 1735 (23.7) & \multirow[t]{4}{*}{$0.718^{\mathrm{a}}$} \\
\hline $22-25$ years & $1984(26.0)$ & $81(24.5)$ & $1903(26.0)$ & \\
\hline $25-30$ years & $1769(23.2)$ & $71(21.5)$ & $1698(23.2)$ & \\
\hline$\geq 30$ years & $2069(27.1)$ & $96(29.1)$ & $1973(27.0)$ & \\
\hline \multicolumn{5}{|l|}{ Gender } \\
\hline Female & $5446(71.3)$ & $289(87.6)^{*}$ & $5157(70.6)^{* *}$ & \multirow[t]{2}{*}{$<0.001^{\mathrm{a}}$} \\
\hline Male & $2193(28.7)$ & $41(12.4)^{* * *}$ & $2152(29.4)^{*}$ & \\
\hline \multicolumn{5}{|l|}{ Occupation } \\
\hline Employed & $2768(36.2)$ & $115(34.8)$ & $2653(36.3)$ & \multirow[t]{6}{*}{$0.405^{\mathrm{b}}$} \\
\hline Unemployed & $2672(35)$ & $122(37.0)$ & 2550 (34.9) & \\
\hline Housewife & $368(4.8)$ & $22(6.7)$ & $346(4.7)$ & \\
\hline Retired & $36(0.5)$ & $1(0.3)$ & $35(0.5)$ & \\
\hline Self-employed & 757 (9.9) & $34(10.3)$ & $723(9.9)$ & \\
\hline Other status & $1038(13.6)$ & $36(10.9)$ & $1002(13.7)$ & \\
\hline \multicolumn{5}{|l|}{ Family history of mental disorder } \\
\hline Yes & $3335(43.7)$ & $169(51.2)^{*}$ & $3166(43.3)^{* *}$ & \multirow[t]{3}{*}{$<0.001^{\mathrm{a}}$} \\
\hline No & $4046(53.0)$ & $142(43.0)^{* *}$ & $3904(53.4)^{*}$ & \\
\hline Don't know (adopted child) & $258(3.4)$ & $19(5.8)^{*}$ & $239(3.3)^{* *}$ & \\
\hline \multicolumn{5}{|l|}{ Previous use of psychotropic drugs (N, \%) } \\
\hline Yes, not currently & $1177(15.4)$ & $71(21.5)^{*}$ & $1106(15.1)^{* *}$ & \multirow[t]{3}{*}{$<0.001^{\mathrm{a}}$} \\
\hline Yes, currently & $808(10.6)$ & $78(23.6)^{*}$ & $730(10.0)^{* *}$ & \\
\hline No & $5654(74.0)$ & $181(54.8)^{* *}$ & $5473(74.9)^{*}$ & \\
\hline \multicolumn{5}{|l|}{ Educational level (N, \%) } \\
\hline Less than primary school & $86(1.1)$ & $4(1.2)$ & $82(1.1)$ & \multirow[t]{4}{*}{$0.941^{\mathrm{b}}$} \\
\hline Primary school & $483(6.3)$ & $22(6.7)$ & $461(6.3)$ & \\
\hline Secondary school & $4721(61.8)$ & $206(62.4)$ & $4515(61.8)$ & \\
\hline University degree & $2349(30.8)$ & $98(29.7)$ & $2251(30.8)$ & \\
\hline \multicolumn{5}{|l|}{ Ethnicity (N, \%) } \\
\hline Caucasian & 3459 (45.3) & $176(53.3)^{*}$ & $3283(44.9)^{* *}$ & \multirow[t]{5}{*}{$<0.001^{b}$} \\
\hline African American & $773(10.1)$ & $25(7.6)$ & $748(10.2)$ & \\
\hline Mulatto $^{\mathrm{d}}$ & $2958(38.7)$ & $101(30.6)^{* *}$ & $2857(39.1)^{*}$ & \\
\hline Asian & $87(1.1)$ & $3(0.9)$ & $84(1.1)$ & \\
\hline Other & $294(3.8)$ & $25(7.6)^{*}$ & $337(4.6)^{* *}$ & \\
\hline \multicolumn{5}{|l|}{ Marital status (N, \%) } \\
\hline Single & $4849(63.5)$ & $191(57.9)$ & 4658 (63.7) & \multirow[t]{5}{*}{$0.129^{\mathrm{a}}$} \\
\hline Married & $1021(13.4)$ & $45(13.6)$ & $976(13.4)$ & \\
\hline Stable union & $787(10.3)$ & $42(12.7)$ & $745(10.2)$ & \\
\hline Divorced/Widow & $481(6.3)$ & $22(6.7)$ & $459(6.3)$ & \\
\hline Other & $501(6.6)$ & $30(9.1)$ & $471(6.4)$ & \\
\hline Religion (N, \%) & & & & \\
\hline Catholic & $2305(30.2)$ & $94(28.5)$ & 2211 (30.3) & $0.027^{\mathrm{a}}$ \\
\hline Protestant & $1864(24.2)$ & $67(20.3)$ & $1797(24.6)$ & \\
\hline Spiritist & $619(8.1)$ & $35(10.6)$ & $584(8.0)$ & \\
\hline Agnostic & $1203(15.7)$ & $68(20.6)^{*}$ & $1135(15.5)^{* *}$ & \\
\hline Other & $1648(21.8)$ & $66(20.0)$ & $1582(21.6)$ & \\
\hline Gross monthly income (N, \%) & & & & \\
\hline Less than 310.00 USD & $2806(36.7)$ & $114(34.5)$ & $2692(36.8)$ & $0.099^{\mathrm{a}}$ \\
\hline Between 310.00 USD and 931.00 USD & $2549(33.4)$ & $129(39.1)$ & $2420(33.1)$ & \\
\hline Between 931.00 USD and 1863.00 USD & $736(9.6)$ & $34(10.3)$ & $702(9.6)$ & \\
\hline More than 1863.00 USD & $382(0.5)$ & $10(3.0)$ & $372(5.1)$ & \\
\hline Don't know/Not informed & $11.66(15.3)$ & $43(13.0)$ & $1123(15.4)$ & \\
\hline Positive screening for a MDE $(\mathrm{N}, \%)$ & $2201(28.8)$ & $218(66.1)^{*}$ & $1983(27.1)^{* *}$ & $<0.001^{\mathrm{a}}$ \\
\hline Positive screening for a bipolar spectrum disorder (N, \%) & $585(7.7)$ & $50(15.2)^{*}$ & $535(7.3)^{* *}$ & $<0.001^{\mathrm{a}}$ \\
\hline Positive screening for nicotine dependence $(\mathrm{N}, \%)$ & $459(6.0)$ & $22(6.7)$ & $437(6.0)$ & $0.607^{\mathrm{a}}$ \\
\hline Positive screening for alcoholism $(\mathrm{N}, \%)$ & $1759(23.0)$ & $87(26.4)$ & $1672(22.9)$ & $0.141^{\mathrm{a}}$ \\
\hline Positive screening for skin picking disorder $(\mathrm{N}, \%)$ & $259(3.4)$ & $232(3.2)^{* *}$ & $27(8.2)^{*}$ & $<0.001^{\mathrm{a}}$ \\
\hline Positive screening for trichotillomania $(\mathrm{N}, \%)$ & $110(1.4)$ & $105(1.4)$ & $5(1.5)$ & $0.813^{\mathrm{b}}$ \\
\hline Positive screening for suicidal ideation (N, \%) & $1909(25.0)$ & $160(48.5)^{*}$ & $1749(23.9)^{* *}$ & $<0.001^{\mathrm{a}}$ \\
\hline
\end{tabular}

Abbreviations: $\mathrm{FA}$ = food addiction; $\mathrm{MDE}=$ major depressive episode.

*Observed was higher than expected in this cell (adjusted residual $>2$ ).

$* *$ Observed was lower than expected in this cell (adjusted residual $<-2$ ).

Statistically significant results are in bold.

a Pearson's chi-square test.

b Fisher's Exact test.

c Two-tailed Student's $t$-test.

${ }^{\mathrm{d}}$ Refers to an ethnic group of mixed white and black ancestry. 
dimensions, the scores of each SCL-90 domain were entered as continuous independent variables in the model. For the association of food addiction with suicidal ideation, the PHQ-9 question 9 response was entered in the model as a categorical variable. For the associations of food addiction and trauma domains, the scores of each individual ETISR-SF domain were entered as continuous independent variables. All other independent variables were dichotomous. All multivariable models were adjusted by background sociodemographic and psychopathological variables as indicated. We applied Bonferroni correction to adjust statistical significance levels in multivariable models for multiple comparisons.

The associations of food addiction and each WHOQOL-Bref domain (dependent variables) were analyzed through separate analysis of covariance (ANCOVA) models. Each model was adjusted by age, sex, occupation, family history of mental disorders, previous use of psychotropic drugs, education level, ethnicity, marital status, gross monthly income, and presence of a positive screen for a major depressive episode, bipolar spectrum disorder, suicidal ideation, nicotine dependence, alcoholism, and SPD. We estimated the effect size of statistically significant associations of food addiction and QoL domains with partial eta squared $\left(\eta_{\mathrm{p}}{ }^{2}\right)$; effect sizes were regarded as small, medium and large when $0.01<\eta_{\mathrm{p}}{ }^{2}<0.06,0.06 \leq \eta_{\mathrm{p}}{ }^{2}<0.14$, and $\eta_{\mathrm{p}}{ }^{2} \geq 0.14$, respectively (Cohen, 1992). Statistical significance was set at an alpha level of 0.05 .

\section{Results}

\subsection{Prevalence and sociodemographic correlates of food addiction}

The prevalence of food addiction in the current sample was $4.32 \%$ (95\% CI: $3.89-4.80 \%$ ); the prevalence rates of mild, moderate, and severe food addiction, respectively, were $1.02 \%$ (95\%CI: $0.82-1.27 \%$ ), $1.20 \%$ (95\%CI: $0.98-1.48 \%$ ), and $2.09 \%$ (95\%CI: $1.80-2.44 \%$ ). The prevalence of food addiction was significantly higher among females
(Table 1). Moreover, participants with food addiction had a significantly greater likelihood of having a positive family history of mental disorder, to report both lifetime and current use of psychotropic drugs, and of having a Caucasian ethnicity (Table 1).

\subsection{Psychopathological correlates of food addiction}

Participants with food addiction were significantly more likely to have a positive screen for a major depressive episode, bipolar spectrum disorder, SPD, and suicidal ideation. However, only the associations with a major depressive episode $\left(\mathrm{OR}_{\mathrm{adj}}=4.41\right)$, bipolar spectrum disorder $\left(\mathrm{OR}_{\mathrm{adj}}=1.98\right)$, and SPD $\left(\mathrm{OR}_{\mathrm{adj}}=2.02\right)$ survived multivariable adjustment to sociodemographic variables, while the association with suicidal ideation was rendered non-significant (Table 2). Participants with food addiction did not significantly differ from those without food addiction regarding the prevalence of co-occurring positive screens for nicotine dependence, alcohol use disorder, and trichotillomania (Table 2).

After multivariable adjustment for sociodemographic variables, participants with food addiction had significantly higher scores on the SCL-90R psychopathological dimensions of interpersonal sensitivity, depression, and hostility, whilst scores on the paranoid ideation dimension was significantly lower compared to participants without food addiction (Table 2).

Participants with food addiction had significantly higher scores in the ETISR-SF physical abuse, psychological abuse, and sexual abuse domains (Table 2). However, only associations of food addiction with psychological abuse and sexual abuse domains survived multivariable adjustment to sociodemographic and psychopathological confounders (Table 2).

\subsection{Associations of food addiction and quality of life domains}

Participants with food addiction had significantly reduced physical,

Table 2

Psychopathological correlates of food addiction (FA).

\begin{tabular}{|c|c|c|c|c|}
\hline \multirow[t]{2}{*}{ Variable } & \multicolumn{2}{|l|}{ Crude } & \multicolumn{2}{|l|}{ Adjusted $^{\mathrm{a}}$} \\
\hline & OR $(95 \% \mathrm{CI})$ & $P$-value ${ }^{\mathrm{d}}$ & OR $(95 \% \mathrm{CI})$ & $P$-value ${ }^{\mathrm{d}}$ \\
\hline Positive screen for a MDE (PHQ-9) $)^{a}$ & $5.228(4.141-6.600)$ & $<0.001$ & $4.412(3.460-5.626)$ & $<0.001$ \\
\hline Positive screen for BSD (HCL-32) ${ }^{\mathrm{a}}$ & $2.261(1.654-3.090)$ & $<0.001$ & $1.989(1.439-2.750)$ & $<0.001$ \\
\hline Positive screen for nicotine dependence (FTND) ${ }^{\mathrm{a}}$ & $1.123(0.724-1.744)$ & 0.607 & $0.930(0.584-1.479)$ & 0.758 \\
\hline Positive screen for alcohol use disorder (AUDIT) ${ }^{\mathrm{a}}$ & $1.207(0.940-1.550)$ & 0.141 & $1.178(0.907-1.530)$ & 0.218 \\
\hline Positive screen for skin picking disorder (SPSQ) ${ }^{\mathrm{a}}$ & $2.718(1.800-4.105)$ & $<0.001$ & $2.022(1.319-3.098)$ & 0.001 \\
\hline Positive screen for trichotillomania (MIDI) ${ }^{\mathrm{a}}$ & $1.056(0.440-2.535)$ & 0.907 & $0.916(0.367-2.285)$ & 0.851 \\
\hline Positive screen for suicidal ideation (PHQ-9) ${ }^{\mathrm{a}, \mathrm{b}}$ & $2.992(2.396-3.736)$ & $<0.001$ & $1.254(0.963-1.634)$ & 0.093 \\
\hline \multicolumn{5}{|l|}{ Psychopathological dimensions (SCL-90R) ${ }^{\mathrm{a}, \mathrm{c}}$} \\
\hline Somatization & $1.171(0.959-1.430)$ & 0.120 & $1.099(0.892-1.354)$ & 0.375 \\
\hline Obsessive Compulsive & $0.944(0.755-1.181)$ & 0.616 & $0.974(0.778-1.220)$ & 0.820 \\
\hline Interpersonal sensitivity & $1.892(1.507-2.376)$ & $<0.001$ & $2.013(1.588-2.551)$ & $<0.001$ \\
\hline Depression & $1.675(1.319-2.129)$ & $<0.001$ & $1.429(1.114-1.832)$ & 0.005 \\
\hline Anxiety & $0.860(0.641-1.154)$ & 0.315 & $0.794(0.588-1.074)$ & 0.134 \\
\hline Hostility & $1.288(1.092-1.520)$ & 0.003 & $1.298(1.096-1.538)$ & 0.002 \\
\hline Phobic anxiety & $1.149(0.965-1.368)$ & 0.118 & $1.120(0.937-1.339)$ & 0.214 \\
\hline Paranoid ideation & $0.772(0.624-0.954)$ & 0.016 & $0.776(0.622-0.969)$ & 0.025 \\
\hline Psychoticism & $0.835(0.648-1.077)$ & 0.165 & $0.966(0.742-1.257)$ & 0.795 \\
\hline \multicolumn{5}{|l|}{ Early-life Trauma (ETISR-SF) $^{\mathrm{a}, \mathrm{b}, \mathrm{c}}$} \\
\hline General trauma & $1.030(0.975-1.089)$ & 0.290 & $1.013(0.955-1.076)$ & 0.662 \\
\hline Physical abuse & $0.909(0.835-0.989)$ & 0.028 & $0.967(0.882-1.059)$ & 0.469 \\
\hline Psychological abuse & $1.223(1.141-1.312)$ & $<0.001$ & $1.106(1.027-1.190)$ & 0.008 \\
\hline Sexual abuse & $1.137(1.067-1.211)$ & $<0.001$ & $1.094(1.023-1.169)$ & 0.008 \\
\hline
\end{tabular}

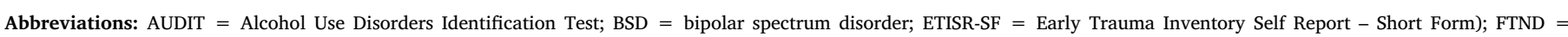

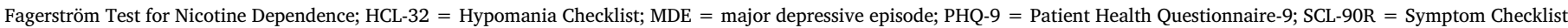
90 revised.

${ }^{a}$ Adjusted for age, gender, education, ethnicity, religion, family history of mental disorders, lifetime history of psychotropic medication use and gross monthly income.

${ }^{\mathrm{b}}$ Adjusted additionally for a positive screen for a MDE, BSD, nicotine dependence, alcohol use disorder, and skin picking disorder.

c Per unity increase in dimension score.

${ }^{\mathrm{d}}$ Bold values are significant at a $\%$ alpha level after Bonferroni correction for multiple comparisons. 


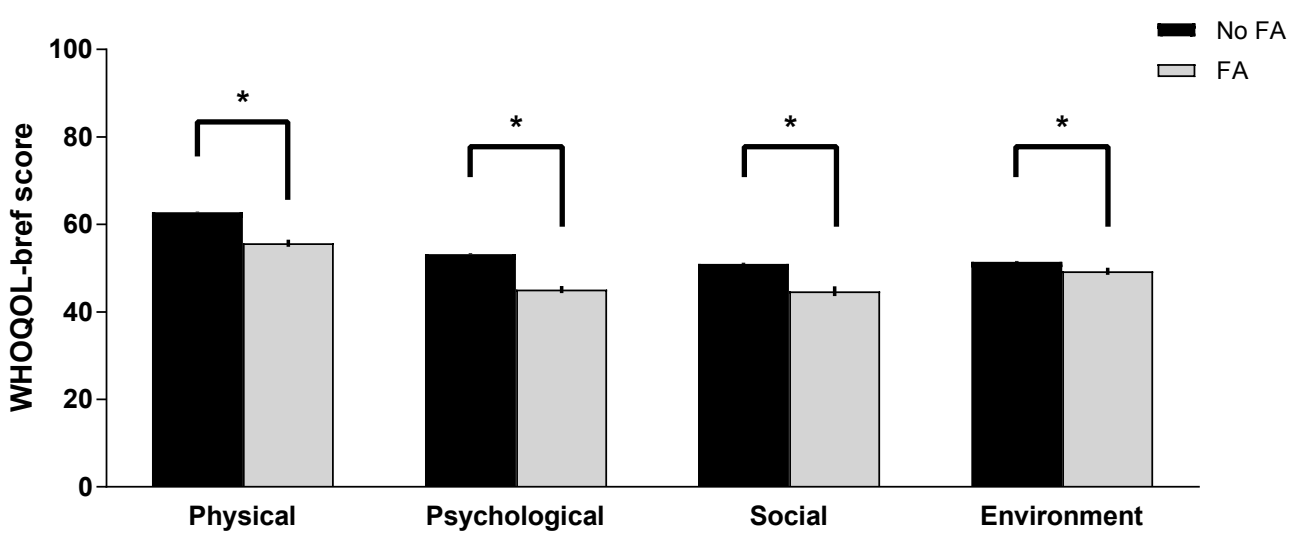

Fig. 1. Associations of food addiction (FA) and physical, psychological, social and environment quality of life as assessed with the WHOQOL-Bref. ${ }^{*} P<0.05$ (separate ANCOVA models adjusted for sociodemographic and psychopathological variables; see Methods section for further details). Scores of WHOQOL-Bref domains are presented as means and $95 \%$ CIs.

Health-related quality-of-life domain

psychological, social, and environment QoL domains after multivariable adjustment to sociodemographic and psychopathological covariates (all $P<0.001$; Fig. 1). Effect sizes of those associations were large $\left(\eta_{\mathrm{p}}{ }^{2}=0.342\right.$ for physical QoL; $\eta_{\mathrm{p}}{ }^{2}=0.451$ for psychological QoL; $\eta_{\mathrm{p}}{ }^{2}=0.202$ for social QoL; and $\eta_{\mathrm{p}}{ }^{2}=0.241$ for environment QoL). However, there were no statistically significant differences on WHOQOL-Bref domains emerged when participants with food addiction were stratified according to severity (i.e., mild, moderate or severe). These data are available upon request to the authors.

\section{Discussion}

The prevalence of food addiction was found to be $4.32 \%$ in our sample, and was more prevalent among females. Most epidemiological studies of food addiction to date have been conducted in the US, with a few performed in other developed nations (Pursey et al., 2014). It has been hypothesized that food addiction may at least partly contribute to the obesity epidemic (Schulte et al., 2015; Volkow et al., 2013a, b). The prevalence of food addiction was lower in our sample compared to previous studies (Pursey et al., 2014). This difference may be due to the inclusion of clinical samples seeking treatment for overweight/obesity in several previous surveys (Pursey et al., 2014). Furthermore, in 2015 the prevalence of obesity among adults was higher in the US than in Brazil, which might account for this difference (Afshin et al., 2017). Our findings are in agreement with previous studies that observed a higher prevalence of food addiction among females (Pursey et al., 2014), which may also contribute to the higher global prevalence of obesity among females (Afshin et al., 2017). Although potential mechanisms underlying a higher prevalence of food addiction among females are likely multifactorial, there is preclinical and clinical evidence for gender-related differences in craving to highly palatable foods that could be at least partly mediated by effects of sex hormones on brain reward circuits (see Hallam et al. (2016) for a wider discussion).

We observed a higher prevalence of a positive screening for a major depressive episode, bipolar spectrum disorder, and SPD in participants with food addiction compared to those without food addiction. Several earlier reports found an association of food addiction with depressive symptoms though many of those previous studies were conducted in clinical samples (Chao et al., 2017a; Gearhardt et al., 2009b; Gearhardt et al., 2013; Granero et al., 2014). Thus, our data provide further support for this association in a large non-clinical sample. To our knowledge, no previous study has examined the co-occurrence of food addiction as defined by the YFAS and bipolar disorder. However, our data is consistent with a previous hypothesis that altered reward circuits in the brain may contribute to compulsive overeating in people with bipolar disorder (McIntyre et al., 2007). Functional aberrations in the functioning of the hypothalamic-pituitary-adrenal (HPA) axis may also in theory contribute to the meaningful co-occurrence of food addiction and a positive screen for mood disorders observed in our sample although more conclusive evidence is awaited (Belvederi Murri et al., 2016; Kalon et al., 2016; Parker et al., 2003). Furthermore, a high prevalence of co-occurring binge-eating disorder and bulimia nervosa, which are related to food addiction, has been observed among patients with bipolar disorder (McElroy et al., 2016; Woldeyohannes et al., 2016). The association of food addiction and SPD provides some support to recent theoretical frameworks that conceptualize SPD as a behavioural addiction (Chamberlain et al., 2016; Odlaug and Grant, 2010b). However, the prevalence of trichotillomania was not significantly higher among participants with food addiction, perhaps reflecting different neurobiological mechanisms compared to SPD (Chamberlain et al., 2016). Interestingly, a previous report found a high prevalence of SPD but not of trichotillomania in a clinical sample of morbidly obese patients (Schmidt et al., 2012). Finally, contrary to our hypothesis, in our sample food addiction was not associated with a higher prevalence of alcohol use disorder or nicotine dependence. However, these data are in accordance to previous studies conducted in clinical (Berenson et al., 2015; Meule et al., 2014) and non-clinical (Gearhardt et al., 2009b) samples. A previous large-scale epidemiological study found that a family history of alcoholism had a lower influence on drinking behavior in obese compared to non-obese individuals (Gearhardt and Corbin, 2009). In addition, food addiction and alcohol/nicotine use disorders may to some extent engage shared neurobiological mechanisms although those conditions may also be viewed as competing addictions as proposed by McIntyre et al. (2007). Nevertheless, further neurobiological investigations are warranted to explore potential mechanisms underpinning the epidemiological observations herein verified.

We observed that food addiction was independently associated with early life physical and sexual abuse. This finding is consistent with a previous prospective investigation that verified that a history of child abuse increases the risk of food addiction among women (Mason et al., 2013). Moreover, a recent cross-sectional study observed a significant association of childhood maltreatment and food addiction in a clinical sample (Imperatori et al., 2016). A meta-analysis indicates that childhood maltreatment could be a risk factor for obesity (Danese and Tan, 2014). Future studies are warranted in order to test whether food addiction may mediate the association of early life trauma and obesity.

Food addiction was associated with impaired QoL across all domains evaluated in the current study after multivariable adjustment to sociodemographic and psychopathological variables. To our knowledge this is the first survey conducted in a non-clinical sample to investigate the independent associations of food addiction and QoL dimensions. These data suggest that efforts to remediate food addiction may consider QoL as a possible outcome, notwithstanding our data deserve 
replication.

This study has several limitations. First, we enrolled a convenience web-based sample with a predominance of young females that may not be representative of the Brazilian population, and thus selection bias cannot be ruled out. Second, although we used validated self-report measures in our study, a positive screen for food addiction or other cooccurring disorders was not confirmed with a clinical diagnosis. Third, in this web-based survey we could not reliably assess body mass index as a surrogate measure of overweight/obesity, whilst constructs related to food addictions (e.g. weight cycling or binge-eating) were not measured in the current study. Fourth, the cross-sectional design of the current study precluded the establishment of causal inferences. On the other hand, strengths of our study include the recruitment of a large sample, and the employment of validated instruments with a widespread use in the scientific community. Furthermore, anonymous participation by internet provides a setting with low desirability bias to answer these instruments.

In conclusion, this survey suggests that food addiction is a common condition in a middle-income country like Brazil although prevalence rates may be lower compared to the US. Furthermore, food addiction was associated with a higher prevalence of a positive screen for depression, bipolar spectrum disorder, and skin picking disorder. Finally, food addiction appeared to have an independent detrimental effect on all QoL dimensions assessed in this study. Efforts towards the early recognition and treatment of food addiction are warranted, while future studies may assess whether food addiction may mediate the well-known association of mood disorders and obesity (de Melo et al., 2017; Liu et al., 2013, 2014). Finally, the putative associations of food addiction and other behavioural addictions and impulse control disorders are relevant research directions opened by the current study.

\section{Conflicts of interest}

Drs. Nunes-Neto, Köhler, Schuch, Solmi, Vancampfort, Quevedo, Maes, Stubbs, and Carvalho declare no conflicts of interest. Dr. Murru has received Continuing Medical Education-related honoraria or consulting fees from Adamed, AstraZeneca, Bristol-MyersSquibb, Janssen, Lundbeck, and Otsuka. Dr Vieta has received grants and served as a consultant, advisor, or CME speaker for the following entities: AB-Biotics, Allergen, AstraZeneca, Bristol-Myers-Squibb, Ferrer, Forest Research Institute, Gedeon Richter, Glaxo-Smith-Kline, Janssen, Lundbeck, Otsuka, Pfizer, Roche, Sanofi-Aventis, Servier, Shire, Sunovion, Takeda, Telefonica, the Brain and Behavior Foundation, the Spanish Ministry of Science and Innovation (Centro de Investigación Biomédica en Red de Salud Mental), the Seventh European Framework Programme (European Network of Bipolar Research Expert Centers), and the Stanley Medical Research Institute. Dr McIntyre has received research grant support from Lundbeck, Janssen Ortho, Shire, Purdue, AstraZeneca, Pfizer, Otsuka, Allergan, Stanley Medical Research Institute; speaker/consultation fees from Lundbeck, Pfizer, AstraZeneca, Elli-Lilly, Janssen Ortho, Purdue, Johnson \& Johnson, Moksha8, Sunovion, Mitsubishi, Takeda, Forest, Otsuka, Bristol-Myers Squibb (BMS), and Shire. Dr McElroy has been a consultant to or member of the scientific advisory boards of Avanir, Bracket, F. Hoffmann-La Roche Ltd., Mitsubishi Tanabe Pharma America, Myriad, Naurex, Novo Nordisk, Otsuka, Shire, and Sunovion. She has been a principal or co-investigator on studies sponsored by Allergan, Azevan, Brainsway, Marriott Foundation, Myriad, National Institute of Mental Health, Naurex, Novo Nordisk, Shire, and Sunovion. She is also an inventor on United States Patent No. 6,323,236 B2, Use of Sulfamate Derivatives for Treating Impulse Control Disorders, and along with the patent's assignee, University of Cincinnati, Cincinnati, Ohio, has received payments from Johnson \& Johnson, which has exclusive rights under the patent.

\section{Role of funding source}

This study was supported by a grant from the Conselho Nacional de Desenvolvimento Científico e Tecnológico (CNPq; Brazil; grant number: 447414/2014-3). The CNPq had no role in study design, data collection and analysis, decision to publish, or preparation of the manuscript.

\section{Acknowledgements}

Dr. Köhler is the recipient of a postdoctoral fellowship award from the Coordenação de Aperfeiçoamento de Pessoal de Nível Superior (CAPES, Brazil). The Translational Psychiatry Program (USA) is funded by the Department of Psychiatry and Behavioral Sciences, McGovern Medical School, The University of Texas Health Science Center at Houston (UTHealth). Laboratory of Neurosciences (Brazil) is one of the centers of the National Institute for Molecular Medicine (INCT-MM) and one of the members of the Center of Excellence in Applied Neurosciences of Santa Catarina (NENASC). Its research is supported by grants from CNPq, FAPESC; Instituto Cérebro e Mente and UNESC. Dr. Quevedo is a 1A CNPq Research Fellow. Dr. Carvalho is the recipient of a research fellowship award from CNPq.

\section{References}

Afshin, A., Forouzanfar, M.H., Reitsma, M.B., Sur, P., Estep, K., Lee, A., Marczak, L. Mokdad, A.H., Moradi-Lakeh, M., Naghavi, M., Salama, J.S., Vos, T., Abate, K.H., Abbafati, C., Ahmed, M.B., Al-Aly, Z., Alkerwi, A., Al-Raddadi, R., Amare, A.T., Amberbir, A., Amegah, A.K., Amini, E., Amrock, S.M., Anjana, R.M., Arnlov, J., Asayesh, H., Banerjee, A., Barac, A., Baye, E., Bennett, D.A., Beyene, A.S., Biadgilign, S., Biryukov, S., Bjertness, E., Boneya, D.J., Campos-Nonato, I., Carrero, J.J., Cecilio, P., Cercy, K., Ciobanu, L.G., Cornaby, L., Damtew, S.A., Dandona, L., Dandona, R., Dharmaratne, S.D., Duncan, B.B., Eshrati, B., Esteghamati, A., Feigin, V.L., Fernandes, J.C., Furst, T., Gebrehiwot, T.T., Gold, A., Gona, P.N., Goto, A., Habtewold, T.D., Hadush, K.T., Hafezi-Nejad, N., Hay, S.I., Horino, M., Islami, F., Kamal, R., Kasaeian, A., Katikireddi, S.V., Kengne, A.P., Kesavachandran, C.N., Khader, Y.S., Khang, Y.H., Khubchandani, J., Kim, D., Kim, Y.J., Kinfu, Y., Kosen, S., Ku, T., Defo, B.K., Kumar, G.A., Larson, H.J., Leinsalu, M., Liang, X., Lim, S.S., Liu, P., Lopez, A.D., Lozano, R., Majeed, A., Malekzadeh, R., Malta, D.C., Mazidi, M., McAlinden, C., McGarvey, S.T., Mengistu, D.T., Mensah, G.A., Mensink, G.B.M., Mezgebe, H.B., Mirrakhimov, E.M., Mueller, U.O., Noubiap, J.J., Obermeyer, C.M., Ogbo, F.A., Owolabi, M.O., Patton, G.C., Pourmalek, F., Qorbani, M., Rafay, A., Rai, R.K., Ranabhat, C.L., Reinig, N., Safiri, S., Salomon, J.A., Sanabria, J.R., Santos, I.S., Sartorius, B., Sawhney, M., Schmidhuber, J., Schutte, A.E., Schmidt, M.I., Sepanlou, S.G., Shamsizadeh, M., Sheikhbahaei, S., Shin, M.J., Shiri, R., Shiue, I., Roba, H.S., Silva, D.A.S., Silverberg, J.I., Singh, J.A., Stranges, S., Swaminathan, S., TabaresSeisdedos, R., Tadese, F., Tedla, B.A., Tegegne, B.S., Terkawi, A.S., Thakur, J.S., Tonelli, M., Topor-Madry, R., Tyrovolas, S., Ukwaja, K.N., Uthman, O.A., Vaezghasemi, M., Vasankari, T., Vlassov, V.V., Vollset, S.E., Weiderpass, E., Werdecker, A., Wesana, J., Westerman, R., Yano, Y., Yonemoto, N., Yonga, G., Zaidi, Z., Zenebe, Z.M., Zipkin, B., Murray, C.J.L., 2017. Health effects of overweight and obesity in 195 Countries over 25 years. N. Engl. J. Med. 377 (1), 13-27.

American Psychiatric Association, 2013. Diagnostic and Statistical Manual of Mental Disorders (DSM- $5^{\circ}$ ). American Psychiatric Pub.

Angst, J., Adolfsson, R., Benazzi, F., Gamma, A., Hantouche, E., Meyer, T.D., Skeppar, P., Vieta, E., Scott, J., 2005. The HCL-32: towards a self-assessment tool for hypomanic symptoms in outpatients. J. Affect. Disord. 88 (2), 217-233.

Belvederi Murri, M., Prestia, D., Mondelli, V., Pariante, C., Patti, S., Olivieri, B., Arzani, C., Masotti, M., Respino, M., Antonioli, M., Vassallo, L., Serafini, G., Perna, G., Pompili, M., Amore, M., 2016. The HPA axis in bipolar disorder: systematic review and meta-analysis. Psychoneuroendocrinology 63, 327-342.

Berenson, A.B., Laz, T.H., Pohlmeier, A.M., Rahman, M., Cunningham, K.A., 2015. Prevalence of food addiction among low-income reproductive-aged women. J. women's health 24 (9), 740-744 2002.

Bremner, J.D., Bolus, R., Mayer, E.A., 2007. Psychometric properties of the early trauma inventory-self report. J. Nerv. Ment. Dis. 195 (3), 211-218.

Carissimi, A., 2011. Examinando fatores causais de sintomas psicologicos atraves do SCL$90 \mathrm{R}$ em pacientes com apneia do sono grave (Master's degree dissertation). Universidade Federal do Rio Grande do Sul, Porto Alegre, Brazil.

Carvalho, A.F., Takwoingi, Y., Sales, P.M., Soczynska, J.K., Kohler, C.A., Freitas, T.H., Quevedo, J., Hyphantis, T.N., McIntyre, R.S., Vieta, E., 2015. Screening for bipolar spectrum disorders: a comprehensive meta-analysis of accuracy studies. J. Affect. Disord. 172, 337-346.

Chamberlain, S.R., Lochner, C., Stein, D.J., Goudriaan, A.E., van Holst, R.J., Zohar, J. Grant, J.E., 2016. Behavioural addiction-A rising tide? Eur. Neuropsychopharmacol. J. Eur. Coll. Neuropsychopharmacol. 26 (5), 841-855.

Chao, A.M., Shaw, J.A., Pearl, R.L., Alamuddin, N., Hopkins, C.M., Bakizada, Z.M., Berkowitz, R.I., Wadden, T.A., 2017a. Prevalence and psychosocial correlates of food addiction in persons with obesity seeking weight reduction. Compr. psychiatry 73 , 
97-104.

Chao, A.M., White, M.A., Grilo, C.M., Sinha, R., 2017b. Examining the effects of cigarette smoking on food cravings and intake, depressive symptoms, and stress. Eat. Behav. 24, 61-65.

Choi, Y.J., Lee, W.Y., 2017. The prevalence of suicidal ideation and depression among primary care patients and current management in South Korea. Int. J. Ment. health Syst. 11, 18.

Christenson, G.A., Faber, R.J., de Zwaan, M., Raymond, N.C., Specker, S.M., Ekern, M.D., Mackenzie, T.B., Crosby, R.D., Crow, S.J., Eckert, E.D., et al., 1994. Compulsive buying: descriptive characteristics and psychiatric comorbidity. J. Clin. psychiatry 55 (1), 5-11.

Cohen, J., 1992. A power primer. Psychol. Bull. 112 (1), 155-159.

Cuthbert, B.N., Insel, T.R., 2013. Toward the future of psychiatric diagnosis: the seven pillars of RDoC. BMC Med. 11, 126.

Danese, A., Tan, M., 2014. Childhood maltreatment and obesity: systematic review and meta-analysis. Mol. psychiatry 19 (5), 544-554.

de Melo, L.G.P., Nunes, S.O.V., Anderson, G., Vargas, H.O., Barbosa, D.S., Galecki, P., Carvalho, A.F., Maes, M., 2017. Shared metabolic and immune-inflammatory, oxidative and nitrosative stress pathways in the metabolic syndrome and mood disorders. Prog. neuro-psychopharmacology Biol. psychiatry 78, 34-50.

de Meneses-Gaya, C., Zuardi, A.W., de Azevedo Marques, J.M., Souza, R.M., Loureiro, S.R., Crippa, J.A., 2009. Psychometric qualities of the brazilian versions of the fagerstrom test for nicotine dependence and the heaviness of smoking index. Nicotine Tob. Res. official J. Soc. Res. Nicotine Tob. 11 (10), 1160-1165.

Derogatis, L.R., Melisaratos, N., 1983. The brief symptom inventory: an introductory report. Psychol. Med. 13 (3), 595-605.

Figee, M., Pattij, T., Willuhn, I., Luigjes, J., van den Brink, W., Goudriaan, A., Potenza, M.N., Robbins, T.W., Denys, D., 2016. Compulsivity in obsessive-compulsive disorder and addictions. Eur. Neuropsychopharmacol. J. Eur. Coll. Neuropsychopharmacol. 26 (5), 856-868.

Fleck, M.P., Louzada, S., Xavier, M., Chachamovich, E., Vieira, G., Santos, L., Pinzon, V., 2000. Application of the Portuguese version of the abbreviated instrument of quality life WHOQOL-bref. Rev. saude publica 34 (2), 178-183.

Gearhardt, A.N., Boswell, R.G., White, M.A., 2014. The association of "food addiction" with disordered eating and body mass index. Eat. Behav. 15 (3), 427-433.

Gearhardt, A.N., Corbin, W.R., 2009. Body mass index and alcohol consumption: family history of alcoholism as a moderator. Psychol. Addict. Behav. J. Soc. Psychol. Addict. Behav. 23 (2), 216-225.

Gearhardt, A.N., Corbin, W.R., Brownell, K.D., 2009a. Food addiction: an examination of the diagnostic criteria for dependence. J. Addict. Med. 3 (1), 1-7.

Gearhardt, A.N., Corbin, W.R., Brownell, K.D., 2009b. Preliminary validation of the Yale food addiction scale. Appetite 52 (2), 430-436.

Gearhardt, A.N., Corbin, W.R., Brownell, K.D., 2016. Development of the Yale food addiction scale Version 2.0. Psychol. Addict. Behav. J. Soc. Psychol. Addict. Behav. 30 (1), 113-121.

Gearhardt, A.N., White, M.A., Masheb, R.M., Grilo, C.M., 2013. An examination of food addiction in a racially diverse sample of obese patients with binge eating disorder in primary care settings. Compr. Psychiatry 54 (5), 500-505.

Gearhardt, A.N., White, M.A., Masheb, R.M., Morgan, P.T., Crosby, R.D., Grilo, C.M., 2012. An examination of the food addiction construct in obese patients with binge eating disorder. Int. J. Eat. Disord. 45 (5), 657-663.

Granero, R., Hilker, I., Aguera, Z., Jimenez-Murcia, S., Sauchelli, S., Islam, M.A., Fagundo, A.B., Sanchez, I., Riesco, N., Dieguez, C., Soriano, J., Salcedo-Sanchez, C., Casanueva, F.F., De la Torre, R., Menchon, J.M., Gearhardt, A.N., Fernandez-Aranda, F., 2014. Food addiction in a Spanish sample of eating disorders: DSM-5 diagnostic subtype differentiation and validation data. Eur. Eat. Disord. Rev. J. Eat. Disord. Assoc. 22 (6), 389-396.

Hallam, J., Boswell, R.G., DeVito, E.E., Kober, H., 2016. Gender-related differences in food craving and obesity. Yale J. Biol. Med. 89 (2), 161-173.

Heatherton, T.F., Kozlowski, L.T., Frecker, R.C., Fagerstrom, K.O., 1991. The fagerstrom test for nicotine dependence: a revision of the fagerstrom tolerance questionnaire. Br. J. Addict. 86 (9), 1119-1127.

Imperatori, C., Innamorati, M., Lamis, D.A., Farina, B., Pompili, M., Contardi, A., Fabbricatore, M., 2016. Childhood trauma in obese and overweight women with food addiction and clinical-level of binge eating. Child abuse Negl. 58, 180-190.

Jimenez-Murcia, S., Granero, R., Wolz, I., Bano, M., Mestre-Bach, G., Steward, T., Aguera, Z., Hinney, A., Dieguez, C., Casanueva, F.F., Gearhardt, A.N., Hakansson, A., Menchon, J.M., Fernandez-Aranda, F., 2017. Food addiction in gambling disorder: frequency and clinical outcomes. Front. Psychol. 8, 473.

Kalon, E., Hong, J.Y., Tobin, C., Schulte, T., 2016. Psychological and neurobiological correlates of food addiction. Int. Rev. Neurobiol. 129, 85-110.

Keuthen, N.J., Koran, L.M., Aboujaoude, E., Large, M.D., Serpe, R.T., 2010. The prevalence of pathologic skin picking in US adults. Compr. psychiatry 51 (2), 183-186.

Kroenke, K., Spitzer, R.L., Williams, J.B., 2001. The PHQ-9: validity of a brief depression severity measure. J. general Intern. Med. 16 (9), 606-613.

Lima, A.B., Kohler, C.A., Stubbs, B., Quevedo, J., Hyphantis, T.N., Koyanagi, A., Marazziti, D., Soares, J.C., Vieta, E., Carvalho, A.F., 2017. An exploratory study of the heterogeneity of the jealousy phenomenon and its associations with affective temperaments and psychopathological dimensions in a large Brazilian sample. J. Affect.
Disord. 212, 10-16.

Lima, C.T., Freire, A.C., Silva, A.P., Teixeira, R.M., Farrell, M., Prince, M., 2005 Concurrent and construct validity of the audit in an urban brazilian sample. Alcohol Alcohol. Oxf. Oxfs. 40 (6), 584-589.

Liu, C.S., Carvalho, A.F., Mansur, R.B., McIntyre, R.S., 2013. Obesity and bipolar disorder: synergistic neurotoxic effects? Adv. Ther. 30 (11), 987-1006.

Liu, C.S., Carvalho, A.F., McIntyre, R.S., 2014. Towards a "metabolic" subtype of major depressive disorder: shared pathophysiological mechanisms may contribute to cognitive dysfunction. CNS Neurological Disord. Drug Targets 13 (10), 1693-1707.

Mason, S.M., Flint, A.J., Field, A.E., Austin, S.B., Rich-Edwards, J.W., 2013. Abuse victimization in childhood or adolescence and risk of food addiction in adult women. Obes. (Silver Spring, Md.) 21 (12), E775-E781.

McElroy, S.L., Crow, S., Blom, T.J., Biernacka, J.M., Winham, S.J., Geske, J., CuellarBarboza, A.B., Bobo, W.V., Prieto, M.L., Veldic, M., Mori, N., Seymour, L.R., Bond, D.J., Frye, M.A., 2016. Prevalence and correlates of DSM-5 eating disorders in patients with bipolar disorder. J. Affect. Disord. 191, 216-221.

McIntyre, R.S., McElroy, S.L., Konarski, J.Z., Soczynska, J.K., Bottas, A., Castel, S., Wilkins, K., Kennedy, S.H., 2007. Substance use disorders and overweight/obesity in bipolar I disorder: preliminary evidence for competing addictions. J. Clin. psychiatry 68 (9), 1352-1357.

Meule, A., Gearhardt, A.N., 2014. Five years of the Yale food addiction scale: taking stock and moving forward. Curr. Addict. Rep. 1 (3), 193-205.

Meule, A., Heckel, D., Jurowich, C.F., Vogele, C., Kubler, A., 2014. Correlates of food addiction in obese individuals seeking bariatric surgery. Clin. Obes. 4 (4), 228-236.

Monzani, B., Rijsdijk, F., Cherkas, L., Harris, J., Keuthen, N., Mataix-Cols, D., 2012. Prevalence and heritability of skin picking in an adult community sample: a twin study. American journal of medical genetics. Part B, Neuropsychiatric Genet. Official Publ. Int. Soc. Psychiatric Genet. 159b (5), 605-610.

Odlaug, B.L., Grant, J.E., 2010a. Impulse-control disorders in a college sample: results from the self-administered Minnesota Impulse Disorders Interview (MIDI). Prim. Care Companion J. Clin. Psychiatry 12 (2).

Odlaug, B.L., Grant, J.E., 2010b. Pathologic skin picking. Am. J. drug alcohol abuse 36 (5), 296-303.

Osorio, F.L., Salum, G.A., Donadon, M.F., Forni-Dos-Santos, L., Loureiro, S.R., Crippa, J.A., 2013. Psychometrics properties of Early Trauma Inventory Self Report - Short Form (ETISR-SR) for the Brazilian context. PLoS One 8 (10), e76337.

Parker, K.J., Schatzberg, A.F., Lyons, D.M., 2003. Neuroendocrine aspects of hypercortisolism in major depression. Hormones Behav. 43 (1), 60-66.

Pursey, K.M., Stanwell, P., Gearhardt, A.N., Collins, C.E., Burrows, T.L., 2014. The prevalence of food addiction as assessed by the Yale Food Addiction Scale: a systematic review. Nutrients 6 (10), 4552-4590.

Santos, I.S., Tavares, B.F., Munhoz, T.N., Almeida, L.S., Silva, N.T., Tams, B.D., Patella, A.M., Matijasevich, A., 2013. Sensitivity and specificity of the Patient Health Questionnaire-9 (PHQ-9) among adults from the general population. Cad. Saude Publica 29 (8), 1533-1543.

Saunders, J.B., Aasland, O.G., Babor, T.F., de la Fuente, J.R., Grant, M., 1993. Development of the Alcohol Use Disorders Identification Test (AUDIT): WHO collaborative project on early detection of persons with harmful alcohol consumption-II. Addict. (Abingdon, Engl. 88 (6), 791-804.

Schmidt, F., Korber, S., de Zwaan, M., Muller, A., 2012. Impulse control disorders in obese patients. Eur. Eat. Disord. Rev. J. Eat. Disord. Assoc. 20 (3), e144-147.

Schulte, E.M., Gearhardt, A.N., 2017. Development of the modified Yale food addiction scale version 2.0. Eur. Eat. Disord. Rev. 25 (4), 302-308.

Schulte, E.M., Grilo, C.M., Gearhardt, A.N., 2016. Shared and unique mechanisms underlying binge eating disorder and addictive disorders. Clin. Psychol. Rev. 44, 125-139.

Schulte, E.M., Joyner, M.A., Potenza, M.N., Grilo, C.M., Gearhardt, A.N., 2015. Current considerations regarding food addiction. Curr. psychiatry Rep. 17 (4), 563.

Soares, O.T., Moreno, D.H., Moura, E.C., Angst, J., Moreno, R.A., 2010. Reliability and validity of a brazilian version of the hypomania checklist (HCL-32) compared to the Mood Disorder Questionnaire (MDQ). Rev. Bras. Psiquiatr. 32 (4), 416-423 (Sao Paulo, Brazil : 1999).

Stein, D.J., Kogan, C.S., Atmaca, M., Fineberg, N.A., Fontenelle, L.F., Grant, J.E., Matsunaga, H., Reddy, Y.C., Simpson, H.B., Thomsen, P.H., van den Heuvel, O.A., Veale, D., Woods, D.W., Reed, G.M., 2016. The classification of obsessive-compulsive and related disorders in the ICD-11. J. Affect. Disord. 190, 663-674.

Volkow, N.D., Koob, G.F., McLellan, A.T., 2016. Neurobiologic advances from the brain disease model of addiction. N. Engl. J. Med. 374 (4), 363-371.

Volkow, N.D., Wang, G.J., Tomasi, D., Baler, R.D., 2013a. The addictive dimensionality of obesity. Biol. psychiatry 73 (9), 811-818.

Volkow, N.D., Wang, G.J., Tomasi, D., Baler, R.D., 2013b. Obesity and addiction: neurobiological overlaps. Obes. Rev. Official J. Int. Assoc. Study Obes. 14 (1), 2-18.

WHOQOL-Group, 1998. Development of the World health organization WHOQOL-BREF quality of life assessment. The WHOQOL group. Psychol. Med. 28 (3), 551-558.

Woldeyohannes, H.O., Soczynska, J.K., Maruschak, N.A., Syeda, K., Wium-Andersen, I.K., Lee, Y., Cha, D.S., Xiao, H.X., Gallaugher, L.A., Dale, R.M., Alsuwaidan, M.T., Mansur, R.B., Muzina, D.J., Carvalho, A.F., Jerrell, J., Kennedy, S., McIntyre, R.S., 2016. Binge eating in adults with mood disorders: results from the international mood disorders collaborative project. Obes. Res. Clin. Pract. 10 (5), 531-543. 